Saint Louis University School of Law

Scholarship Commons

All Faculty Scholarship

2014

\title{
Beyond Instructions to Disregard: When Objections Backfire and Interruptions Distract
}

\author{
Molly J. Walker Wilson \\ Saint Louis University School of Law \\ Barbara A. Spellman \\ University of Virginia School of Law \\ Rachel York \\ George Mason University - Department of Psychology
}

Follow this and additional works at: https://scholarship.law.slu.edu/faculty

Part of the Law Commons

\section{Recommended Citation}

Wilson, Molly J. Walker and Spellman, Barbara A. and York, Rachel, Beyond Instructions to Disregard: When Objections Backfire and Interruptions Distract (May 3, 2014).

This Working Paper is brought to you for free and open access by Scholarship Commons. It has been accepted for inclusion in All Faculty Scholarship by an authorized administrator of Scholarship Commons. For more information, please contact erika.cohn@slu.edu, ingah.daviscrawford@slu.edu. 
Running Head: WHEN OBJECTIONS BACKFIRE

\section{DO NOT QUOTE}

Beyond Instructions to Disregard:

When Objections Backfire and Interruptions Distract

Molly J. Walker Wilson

St. Louis University School of Law

$$
\begin{aligned}
& \text { Barbara A. Spellman } \\
& \text { University of Virginia } \\
& \text { Rachel M. York }
\end{aligned}
$$

Florida International University 


\begin{abstract}
Researchers have proposed many explanations for the replicated finding that jurors often fail to disregard evidence when instructed by a judge to do so. We propose a novel explanation: that the act of objecting may cause the effect because an objection (a) draws attention to the testimony and (b) heightens the perceived importance of the testimony (because of the implication that the objecting party wants to prevent jurors from using it). In previous studies, the act of objecting has always been confounded with the presence of the critical (objected-to) testimony. We devised two new experimental conditions that unconfound these factors. We found that whereas objections increase the use of objectedto (incriminating) testimony, random (non-objection) interruptions decrease use of this testimony. We conclude that, unlike random interruptions, an objection communicates to the jurors that an attorney is concerned about the objected-to testimony, increasing the perceived importance of that testimony.
\end{abstract}


Beyond Instructions to Disregard:

When Objections Backfire and Interruptions Distract

It is a familiar scene from a television show: a prosecutor who is cross-examining the defendant asks a question that results in the defendant providing an incriminating response. The defense attorney, recognizing that the question was improper, rises to her feet, calling out, "Objection!" She may explain why she thinks the testimony is inadmissible. The judge then decides either to overrule or to sustain the objection; if the latter, the ruling may come with the instruction: "The jury must disregard the witness's testimony."

Many televisions viewers have probably scoffed at the notion that jurors can disregard incriminating evidence once they've heard it. Our intuitions aside, the question remains: Can jurors ignore information? Do they when instructed to? If jurors don't disregard, why don't they? Most psychological research has suggested that jurors do not entirely disregard inadmissible evidence. In fact, the literature suggests that not only are jurors unable and often unwilling to forget the testimony they have heard (Carretta \& Moreland, 1983; Fein, McCloskey, \& Tomlinson, 1997; Kassin \& Sommers, 1997; Thompson, Fong, \& Rosenham, 1981; Wolf \& Montgomery, 1977), but also that a judge's instruction to disregard inadmissible evidence can actually magnify the impact such evidence has on jurors' guilt decisions and sentencing recommendations (Reinard \& Reynolds, 1978; Sue, Smith, \& Caldwell, 1973; Tanford, 1990). For example, mock jurors in a civil trial who had been told the defendant had insurance but were instructed to disregard this information awarded higher damages to the plaintiff than those jurors who 
thought the defendant had no insurance or those that had been told the defendant did have insurance but were not instructed to disregard the information (Broeder, 1959). The question that remains is why don't jurors disregard inadmissible evidence?

\section{Theoretical Explanations for the Boomerang Effect}

Various theories have been advanced to explain why jurors not only do not disregard inadmissible testimony, but also may even give the testimony more weight after being instructed to disregard it. Some explanations center on a jury's unwillingness to disregard the testimony; others focus on the jury's inability to disregard the testimony.

\section{Unwillingness to Disregard (Social Factors)}

Several theories suggest that even if jurors are able to disregard the crucial testimony, they choose not to. When jurors are unwilling to follow a judge's instruction, it is generally because of social factors (such as jurors' reasoning about the motivation of the witnesses or the reliability of the evidence).

Reactance theory. Reactance theory proposes that jurors are unwilling to follow the judge's instructions to disregard because jurors feel as if these instructions threaten their freedom to consider all available evidence (Brehm \& Brehm, 1981). For example, mock jurors who were specifically and firmly admonished to disregard certain testimony reported a greater desire to consider the inadmissible evidence than jurors who had not received the admonishment. Jurors who felt that their freedom was thus threatened also experienced a "boomerang effect": they were influenced by the very testimony that they had been instructed to disregard (Wolf \& Montgomery, 1977).

Desire for justice. Another reason jurors may fail to disregard evidence is that they want to return a just verdict. Sommers and Kassin (1997) demonstrated that jurors 
are more likely to disregard inadmissible evidence when the evidence seems unreliable. Mock jurors heard a tape containing incriminating evidence. They were then instructed to disregard that evidence because either (a) the information on the tape was illegally obtained or (b) the quality of the recording rendered the information on the tape suspect. Participants were significantly less likely to allow the evidence to influence their verdicts when the reason to do so involved a "technicality" than when it involved the potential for unreliability of the information. Thus, jurors may selectively comply with instructions depending on reasons - and, at least in part, disregarding is a matter of willingness not ability.

Inability to Disregard (Cognitive Factors)

On the other hand, when jurors are unable to disregard testimony, explanations tend to be cognitive. These theories include the ironic process model, belief perseverance, and the story model. They also include the hindsight bias, which suggests that even if jurors could disregard specific testimony, they might not be able to disregard inferences made based on that testimony.

Ironic effects of thought suppression. Research on the ironic effects of thought suppression (Wegner \& Erber, 1992) indicates that a juror who is trying to ignore certain information may end up thinking about it with increased frequency. Wegner and colleagues have discovered that trying not to think of a white bear, for example, actually increases people's tendency to do so (Wegner \& Erber, 1992; Wegner et al., 1987). The harder people try to suppress a certain thought, the more likely it is that this thought will continue to surface (Wegner, 1994). The ironic process model suggests that jurors who attempt to suppress specific testimony while simultaneously attending to other aspects of 
the trial might suffer thought intrusion with respect to the inadmissible testimony. Thus, as a consequence of attempting to forget inadmissible testimony, jurors may actually think more about that very testimony (Clavet, 1996). Moreover, research has shown that people have an especially difficult time suppressing emotionally charged information, such as the type that might surface during a trial (Edwards \& Bryan, 1997).

Belief perseverance. Research on belief perseverance has shown that when participants are given information, particularly with respect to characterizations of human beings, and asked to generate explanations for the information, they are likely to maintain these beliefs even after they have been told that the information is false (Anderson, Lepper, \& Ross, 1980). In one study illustrating this effect, participants read a case study about firefighters. Half of the participants were told that the best firefighters were risk takers and half were told that cautious types made the best firefighters, then they were asked to justify the particular characterization they had read. Next, participants were informed that the characterizations included in the case study had been fabricated specifically for the purposes of the study. When later asked about the relationship between personality and firefighting ability, however, participants seemed to have come to believe the characterizations they had been asked to support with reasons earlier in the study. The authors of the study noted that if jurors have already begun to generate some explanatory structure for certain testimony, subsequent instructions to disregard the testimony would likely fail as a result of belief perseverance (Kassin \& Studebaker, 1998).

Correction comprehension. Whereas belief perseverance focuses on the longevity of a belief, correction comprehension focuses on the ability of people to rectify erroneous 
beliefs. If human beings were perfectly logical machines, they would be able to erase the effects of false information on their understanding of the world upon learning that the information was misleading or false. However, people seem to automatically accept information as they receive it, making the renunciation of that information difficult after the fact (Gilbert, Tafarodi, \& Malone, 1993). Story coherence and constructing narratives. Understanding how individuals construct narratives may help to explain why jurors might incorporate inadmissible testimony into their understanding of events during trial. In order to understand the "story" they are hearing, jurors create a cognitive representation, or schema, gathering and organizing the evidence presented in order to generate a coherent representation of events (Pennington \& Hastie, 1992). Before they can disregard testimony, jurors must deconstruct the narrative they have already constructed, a difficult task (Johnson \& Seifert, 1994). Studies of reading comprehension and directed forgetting show that information that is particularly causal or consequential, and thus tightly incorporated into a narrative, is viewed as particularly important (Trabasso \& van den Broek, 1985) and that as information becomes more meaningful, it becomes more difficult to forget (Geiselman, 1974). Thus, jurors should have a difficult time disregarding a piece of information that is key to the outcome of a story.

Hindsight Bias. Even if particular "facts" presented in testimony could be disregarded, research on the hindsight bias suggests that inferences that jurors had drawn from those facts probably could not be. Hindsight bias occurs when individuals overestimate the importance or likeliness of an event because of a known outcome (Fischhoff, 1975). According to Fischhoff, when individuals are attempting to reconstruct events, once they have a coherent story in mind, they assign causal events 
(events that are deemed to be connected to the outcome of the story) greater importance or obviousness. The result is that the outcome appears to be inevitable in light of those causal events. Of particular relevance is Fischhoff's finding that even when individuals are successful in suppressing specific knowledge leading to an insight or inference, they are unable to suppress insights gleaned from having that specific (outcome-related) information (Rachlinski, 2000). This research suggests that even if jurors were able to suppress thoughts about specific evidence, their verdicts might still be affected by the inferences created as a result of having heard the information.

\section{A New Focus: The Objection}

One piece of the puzzle that has been entirely disregarded (pun intended) is the objection itself. We propose a novel idea: perhaps jurors are unwilling or unable to disregard inadmissible evidence precisely because it is objected to. In other words, the very act of objecting might affect attention to, memory for, and use of the critical information. There are two reasons why an objection might lead to greater use of the objected-to testimony. First, (the cognitive reason) is that the objection creates an interruption that may serve to highlight the objected-to testimony, making it particularly memorable. Second, (the social reason) is that the objection reveals that one party hopes to prevent the jury from using the objected-to evidence, which signals that the evidence may be particularly damaging to that party (and particularly relevant to a verdict determination).

\section{“Objection!” as Interruption}

An objection creates an interruption that may serve to "spotlight" the objected-to testimony. Because the objection-interruption is different from what occurs prior to the 
objection, it may stand out as distinct and unusual. It may also serve to "wake up" jurors and may cause the jury to pay special attention to the objected-to testimony. Several features of the objection situation may exacerbate this effect. Following an objection, jurors may have to wait while the attorneys and the judge confer as to the admissibility of the testimony. Frequently the discussion occurs at sidebar (out of the hearing of the jury), creating a prolonged interruption, which may serve to further increase juror attention to the testimony. Ironically, even a judge's instruction to disregard may extend the time that jurors focus on the testimony, increasing the memorability of that testimony.

Enhanced cognition: Interruptions, attention, and memory. Although objections are courtroom-specific phenomena, objections may function like other types of interruption in attracting attention. Recently, researchers have theorized that an important byproduct of interruptions is a change in how attention is allocated. Investigations examining sources of interruption (such as pain and television commercials) have suggested that certain types of stimuli that cause interruptions can increase attentional demands (Eccleston \& Crombez, 1999; Geiger \& Reeves, 1993; Krugman, 1983). This theory hypothesizes that interruptions activate an increase in attention for targets relevant to the interrupted task, resulting in an increased likelihood that stimuli related to the task will be noticed. One study using an anagram task found that anagrams that were associated with an interruption were better remembered than anagrams associated with task completion (Maentylae \& Sgaramella, 1997). Memory research on the "recency effect" supports the notion that interruptions increase memory for items linked with or close to the interruption. According to research on the recency effect, targets presented last in a series are particularly well remembered (Glanzer \& 
Cunitz, 1966). One critical component of enhanced memory for recent items is the fact that they are distinctive (Baddeley \& Hitch, 1993; Thapar \& Greene, 1993). Just as a target takes on a distinctive character by virtue of being last, a target also is distinct when an interruption follows.

The link between interruptions, attention, and memory has been investigated in a number of contexts, including television commercials (Eccleston \& Crombez, 1999), crime scenes (Williams, Loftus, \& Deffenbacher, 1992), and task completion (Zeigarnik, 1927). Although this type of investigation has never extended to the courtroom environment, evidence from research in other contexts supports the idea that an increase in attention creates a stronger memory for the object of the attention.

Enhanced motivation: The Zeigarnik effect. In 1927, Zeigarnik proposed that interrupting individuals as they perform a task could increase their desire to perform the task and their memory for the task (Zeigarnik, 1927). Kurt Lewin conducted a series of studies in which he measured the frequency with which participants would return to a task they had been prevented from completing. Participants in Lewin's experiments voluntarily chose to return to the uncompleted task $83 \%$ of the time $-100 \%$ if the interruption was caused by a chance event (Lewin, 1928). Results from this experiment suggest that the participants were uncomfortable moving on to a new problem when they had the sense that they had not finished thinking through the first (interrupted) problem. “Objection!” as Meaningful Communication

Another way in which an attorney's objection could influence whether jurors obey instructions to disregard is if the objection communicates something about the relative importance of the objected-to testimony. This communication might be 
particularly important in light of the social theories proposing that jurors are unwilling to disregard testimony.

Reacting against attorney objections. The earlier discussion of reactance theory explained that individuals resent perceived attempts to threaten their freedom to think as they choose (Brehm \& Brehm, 1981). It may be that jurors resist not only a judge's efforts to restrict the information they use, but also react against an attorney's attempt to limit the use of evidence. In fact, although judges are (at least arguably) unbiased, attorneys have a clear agenda, and may be more likely to engender hostility or suspicion in jurors. Any attempt on the part of an attorney to limit use of testimony, therefore, may result in a boomerang effect (Wolf \& Montgomery, 1977).

Objection as signaling importance of testimony. Jurors may also give particular weight to objected-to testimony if the objection signals to them that the testimony is particularly important. An attorney's clear desire to keep testimony out of the record and to prevent jurors from using that testimony might cue jurors that the testimony has serious implications for the verdict. After all, if the testimony were not important, why would the attorney bother to object? Research indicating that jurors disregard evidence if it seems unreliable but not if there is a "technical" reason (Sommers \& Kassin, 1997) suggests that jurors tend to use information they think will assist them in arriving at "the truth". Thus, testimony that seems particularly likely to bear on the guilt or innocence of a defendant (very incriminating evidence, for example) will be considered-especially if its importance is made obvious by virtue of an objection.

Objection Folklore or Litigators' Wisdom about Judicious Use of Objections 
Although the role of objections has not been studied by behavioral scientists, wisdom about limiting the use of objections exists among litigators and has been passed down through manuals and treatises. One guide for attorneys cautions,

... there are often good reasons to refrain from objecting. . . [j]uror reaction . . . becomes a reason to utilize objections wisely and sparingly, but not to stand in fear of making them at all. . . Fear of losing, however, remains a substantial reason to refrain from objecting. No lawyer can predict with certainty that a judge will agree with his or her objections (Lubet, 1997, pp. 266-67).

One of the goals of the current investigation is to test what legal practitioners have already intuited, namely that objections can be counterproductive.

Potential Consequences of Objecting

Suppose that the presence of an objection does affect the processing of, and reasoning about the objected-to information. If the objection enhances use of the testimony, it should do so regardless of whether the testimony is ruled inadmissible or admissible. If the testimony is ruled inadmissible, the objection itself should make the testimony harder to disregard. If the information is ruled admissible such testimony might be weighted more heavily than other testimony. Unlike previous studies, our study included several conditions in which the testimony is admissible in order to determine precisely how an objection influences use of the objected-to testimony.

\section{Typical Conditions for Evaluating Whether Jurors Disregard}

Previous studies of instructions to disregard have not been designed to determine whether the act of objecting itself affects the jury's ability to disregard evidence. To 
demonstrate the failure to disregard, experiments typically use two or three conditions.

In the condition of interest (Objection-Inadmissible), participants hear a contaminant or "critical testimony" (incriminating evidence that should not be allowed to reach the jury), the critical testimony is objected to, the objection is sustained, and the jury is instructed to disregard the testimony. To evaluate whether jurors follow the instruction, verdicts from this Objection-Inadmissible condition are compared to either one or two "baseline" conditions: (a) a No-Testimony condition (in which jurors never hear the critical testimony) and sometimes also (b) a Testimony-Objection-Admissible condition (in which the testimony is present and objected to, but the objection is overruled, so that the jury is allowed to consider the evidence). Researchers have argued that a higher percentage of guilty verdicts in the Testimony-Objection-Inadmissible condition versus the No-Testimony condition demonstrates the extent to which jurors failed to ignore the inadmissible testimony. Researchers have further argued that to the degree that jurors return more guilty verdicts in the Testimony-Objection-Admissible than Testimony-Objection-Inadmissible condition, it demonstrates that jurors are attempting to at least minimize the influence of the inadmissible evidence.

Importantly, in all of these studies, whenever the critical testimony was present, the objection was also present. Hence, the presence of the critical testimony and objection were confounded.

The current design includes five conditions (see Figure 1):

1. No-Testimony: The critical testimony is absent. There is no objection or interruption. 2. Testimony-No-Objection: The critical testimony is present. There is no objection or interruption. 
3. Testimony-Objection-Inadmissible: The critical testimony is present, it is objected to, and the judge sustains the objection and instructs jurors to disregard the testimony.

4. Testimony-Objection-Admissible: The critical testimony is present, it is objected to, and the judge overrules the testimony so that jurors are permitted to consider it.

5. Testimony-Simple-Interruption: The critical testimony is present. There is an interruption following the critical testimony, but the interruption does not contain an objection (i.e., the interruption is devoid of content).

It is important to note that in the Testimony-No-Objection, Testimony-ObjectionAdmissible, and Testimony-Simple-Interruption conditions, jurors hear the testimony and are permitted to consider it. What differs is whether there is any type of interruption, and if there is, whether the interruption contains an objection.

\section{Predictions}

Experiment 1 used the five conditions illustrated in Figure 1. A greater proportion of guilty verdicts indicates a greater use of the critical testimony (that is, a failure to disregard the inadmissible evidence). We predicted:

(1) More guilty verdicts in the Testimony-No-Objection condition than in the NoTestimony condition. Although not theoretically interesting, this difference provides a manipulation check and baseline evaluation of the potency of the critical testimony.

(2) More guilty verdicts in the Testimony-Objection-Inadmissible condition than in the No-Testimony condition. This result is a replication of the "standard" failure-todisregard finding. Of course, such a finding could be due to any of the factors previously mentioned. 
(3) More guilty verdicts in the Testimony-Objection-Admissible condition than in the Testimony-No-Objection condition. In both conditions jurors hear and are allowed to use the critical testimony. We believed, however, that the objection itself would not only focus jurors' attention on the objected-to testimony, making it more memorable, but would also reveal the defense's desire to prevent jurors from using this information in deciding on a verdict.

(4) If prediction (3) holds, we expected that the proportion of guilty verdicts in the Testimony-Simple-Interruption condition would reveal what, in particular, about an objection makes it more likely that jurors will use it. If the Testimony-SimpleInterruption condition yields the same proportion of guilty verdicts as the TestimonyObjection-Admissible condition, it would suggest that what is important about an objection is that it creates an interruption which spotlights the objected-to testimony. If the Testimony-Simple-Interruption condition yields fewer guilty verdicts than the Testimony-Objection-Admissible condition, it would suggest that what is important about an objection is not the interruption per se, but rather the juror's knowledge that one side wanted to hide the testimony.

\section{Method}

\section{Participants}

A total of 225 undergraduates at the University of Virginia participated for psychology course credit. There were 93 men and 132 women ranging in age from 18 to 23. Participants were run singly or in groups of 2 to 12 people.

\section{Design}

Participants were randomly assigned to one of five conditions, summarized in 
Figure 1. All participants read and heard evidence from the same criminal trial. The conditions varied only with respect to whether participants heard a particular piece of incriminating testimony (the "critical" testimony); whether that testimony was objected to; and whether the objection was sustained (with instructions to disregard) or overruled (consideration of the testimony was permitted). In the fifth condition, following the presentation of the critical testimony, a "simple" (non-objection) interruption occurred.

\section{Procedure}

Participants were seated a room designed to resemble a jury room, which had been equipped with a long table and 12 chairs. They were instructed to imagine that they were real jurors in a trial. The experimenter briefly described the witnesses and testimony the jurors would be reading and seeing on the videotape. Participants read the first witness's transcript, then the experimenter read a summary of the transcript aloud. Participants then read the second witness's transcript and again, the experimenter read a summary of the transcript aloud. Participants were then told that they would see a videotape of a segment of a trial, and that they should pay close attention, because they would be asked to render a verdict following their viewing of the videotape. At the conclusion of the videotape, jurors were provided with a standard witness instruction for a criminal trial in the State of Virginia. This instruction provided information about the burden of proof in a criminal trial as well as other instruction relevant to rendering a verdict. Jurors then completed the dependent measures.

\section{Materials}

The materials consisted of a transcript and a videotape of the testimony of several witnesses in a (mock) murder trial. (See Appendix for timing and wording of 
transcripts.) The murder involved the shooting death of a pregnant woman. The defendant, who had been the woman's lover, was accused of having arranged the victim's murder in order to avoid having to pay child support. Importantly, the prosecution's theory of the case was that the defendant killed the victim because she refused to terminate the pregnancy (this theory was key with respect to the critical testimony).

There were five witnesses in the trial. Participants read transcripts of the testimony of the first two witnesses, which included the questions and answers for each witness during direct- and cross-examination. Participants saw the next three witnesses on videotape. Like the transcripts, the videotape included direct- and cross-examination.

Transcripts. The first witness was the victim's friend, Sara Hastings. Hastings testified on behalf of the prosecution, stating that the defendant had known that the victim was pregnant with his child, and that the victim had received several anonymous threatening notes prior to her death. The second witness was a criminologist who testified on behalf of the defendant, noting that statistically, perpetrators tend to issue threats prior to resorting to violence. The criminologist testified that evidence of the defendant's having threatened the victim increased the likelihood that the defendant committed the crime.

Videotape. The first two witnesses on the videotape testified for the prosecution. The first witness was the defendant's best friend, who testified that the defendant had asked him to arrange the murder of the victim. The second witness was the hit man, who testified that the payment he received for the hit came from the defendant. The third witness was the defendant, who testified on his own behalf.

The critical testimony occurred while the defendant was on the witness stand. In 
response to a question from the prosecutor, the defendant blurted out that he had tried to warn the victim. Because he previously denied having had any contact with the victim for months prior to her death, and because the criminologist testified that perpetrators of this type of crime (where the perpetrator wants something from the victim) generally warn or threaten the victim before resorting to violence, this admission was highly incriminating.

Participants saw one of three tapes.

1. The Testimony-No-Objection condition was the most straightforward condition. The tape included the critical testimony consisting of the incriminating admission made by the defendant in which he said that he "tried to warn" the victim. The tape played all the way through without interruption.

2. In the No-Testimony condition, the tape also played all the way through without interruption, but the critical testimony was edited out.

3. In the other three conditions, immediately following the critical testimony, the tape appeared to have been taped over, so that there was a space of 30 seconds when participants saw nothing on the screen but snow.

During the 30 seconds of snow on tape 3 , the experimenter did one of three things. In the Testimony-Simple-Interruption condition, when the tape malfunctioned, the researcher simply explained that part of the tape got erased, and did not provide participants with any information about an objection or judge ruling. In the two "Objection" conditions, the experimenter stood up in front of the participants, and apologized for the interruption, explaining that she must have mistakenly grabbed the "old" tape, in which part of the trial had accidentally been erased. Following this, she 
told the participants that she would explain what was occurring on the tape for the erased segment. She said that the defense attorney had objected to the admission of the defendant (to having warned the victim) on the grounds that at the time the defendant made this statement to the police, he had not been Mirandized-this served as the basis for the defense attorney's request that the prosecutor's question and the defendant's answer be stricken from the record.

In the Testimony-Objection-Admissible condition, participants were told that the judge overruled the defense attorney's objection, so the testimony would stand. (Hence, participants in this condition were not given the instruction to disregard the incriminating testimony.) In the Testimony-Objection-Inadmissible condition, the experimenter told participants that the judge sustained the objection and instructed the jurors to disregard that testimony. The researcher emphasized that the participants should not let this testimony influence their verdict.

Questionnaire. The first three questions asked about guilt. The first question simply asked for a dichotomous guilty/not guilty verdict. The second question asked for a determination of legal guilt on a nine-point scale. The scale ranged from "very certain" of a not guilty verdict to "very certain" of a guilty verdict, with the endpoints being 1 and 9 respectively and with 5 indicating "not sure what verdict to return." The third question asked participants to indicate, on a nine-point scale, how likely they thought it was that the defendant committed the crime of which he was accused (we called this the "gut instinct" question). This third question was included in order to reveal instances in which participants who believed that the defendant did commit the crime did not find legal guilt 
(as might be the case in the Testimony-Objection-Disregard condition if participants were following judge instructions).

\section{Results and Discussion}

We found that participants did follow instructions to disregard to some degree.

We also found that when the testimony was admissible and there was an objection, use of the critical testimony increased. Surprisingly, we found that a simple interruption actually decreased use of the critical testimony. The dramatic difference between Testimony-Objection-Admissible and Testimony-Simple-Interruption conditions are illustrated in Figures 2 and 3. We did not find any differences for the "gut instinct" question (perhaps because of a ceiling effect-most participants thought the defendant committed the bad act), so those results are not included here.

\section{Critical Testimony Matters (Manipulation Check and Prediction 1)}

Hearing the critical testimony increased perceived guilt. Participants in the Testimony-No-Objection condition returned significantly more guilty verdicts (42\%) than those in the No-Testimony condition $(16 \%),\left(\chi^{2}(1, N=90)=7.79, p<.005\right)$. They also rated the defendant as more guilty on the certainty-of-guilt scale, 5.2 vs. $3.6, t(88)=3.95$, $p<.0005$.

\section{Failure to Disregard Occurs (Prediction 2)}

As found in previous research, participants did not completely disregard the critical testimony when instructed to do so although it appears that they follwed instructions to disregard to some degree. Participants in the Testimony-ObjectionInadmissible condition returned more guilty verdicts $(22 \%)$ than those in the NoTestimony condition (16\%). Although this difference was in the predicted direction, it 
was not significant $\left(\chi^{2}(1, N=90)=.65, n s\right)$. However, the more sensitive certainly-ofguilt rating scale revealed that participants in the Testimony-Objection-Inadmissible condition were significantly more certain that the defendant was guilty (4.5) than participants in the No-Testimony condition (3.6), $t(88)=2.46, p<.05$. An Objection (non-significantly) Increases the Use of Critical Testimony (Prediction 3) When participants were permitted to consider the objected-to testimony, they were (non-significantly) more likely to find the defendant guilty than when the testimony was not objected to. Participants in the Testimony-Objection-Admissible condition returned more guilty verdicts than those in the Testimony-No-Objection condition, $51 \%$ vs. $42 \%, \chi^{2}(1, N=90)=.71, n s ;$ they were also more certain of guilt $(5.5)$ than those who did not hear the objection $(5.2), t(88)=.75, n s$. Although these differences are worth noting, neither was significant.

\section{A Simple Interruption Decreases Use of Critical Testimony (Prediction 4)}

Of great importance is the unexpected finding that an interruption decreases use of the critical testimony. Participants in the Testimony-Simple-Interruption condition returned fewer guilty verdicts (24\%) than those in the Testimony-No-Objection condition $(42 \%), \chi^{2}(1, N=90)=3.2, p<.07$. Although the verdict data showed only a marginally significant difference, a t-test revealed that participants were significantly more certain of guilt in the Testimony-No-Objection (5.2) condition than they were in the TestimonySimple-Interruption condition $(4.3)(t(88)=2.00, p<.05)$. It appears that a simple (nonobjection) interruption caused participants to pay less attention to the critical testimony than in any other condition - including the condition in which the testimony was not highlighted in any way. This finding suggests that an interruption that is devoid of any 
meaningful content may serve to distract jurors from the courtroom action, drawing their attention away from the incriminating testimony.

Now the comparison of the Testimony-Objection-Admissible and the TestimonySimple-Interruption conditions becomes crucial. In each condition, participants heard and were permitted to use the testimony, and in each, there was an interruption. The difference was whether the interruption was a content-free event or had meaning (i.e., included an objection). In fact, participants in the Testimony-Objection-Admissible condition rendered more guilty verdicts $(51 \%)$ than those in the Testimony-SimpleInterruption condition $\left.(24 \%), \chi^{2}(1, N=90)=6.81, p<.01\right)$. Moreover, participants were significantly more certain of guilt in the former condition, $(5.5$, vs. 4.3$), t(88)=-2.83, p<$ .01. This difference suggests that although the "event" of a non-objection interruption decreases use of the testimony, an objection-interruption increases use of the testimony. It appears that when one side objects to testimony, it communicates something important to jurors, namely that the testimony in question may be particularly important (or damaging).

\section{Summary and Implications}

Experiment 1 provided additional insight into the role the objection might play in the failure-to-disregard phenomenon. Results suggested that a mere "interruption" decreases use of the critical testimony, while an objection-interruption can increase use of the critical testimony. Thus, we believe that the meaning conveyed by the objection not only results in a greater number of guilty verdicts when the testimony may be used (comparing the Testimony-Objection-Admissible to the Testimony-Simple-Interruption conditions) but also in the standard situation when jurors are instructed that they may not 
use the testimony (comparing the Testimony-Objection-Inadmissible condition to the NoTestimony condition).

\section{Experiment 2}

Our goal in Experiment 2 was to modify the Testimony-Simple-Interruption condition, making the interruption less dramatic (and possibly less distracting) and to see, with this change, whether we would replicate the most important findings from Experiment 1 . Experiment 2 used a relatively simple design including only three conditions: Testimony-No-Objection, Testimony-Objection-Admissible, and TestimonySimple-Interruption. In all three of these conditions, the critical testimony was present and admissible, so the question of whether jurors disregard inadmissible testimony was not at issue. (Thus, we are the first to study the effect of instructions-to-disregard without any instructions to disregard.) The only aspect that differed between conditions was the presence and nature of the interruption. (Note: because all conditions contained the testimony, we will drop the word "Testimony" from the condition labels.)

Experiment 2 used new materials, allowing us to make changes to the procedure. First, we reduced the interruption interval from 30 seconds in Experiment 1 to 10 seconds in Experiment 2. We thought that would help avoid losing participants' attention and focus during the pause. Second, Experiment 2 did not require the experimenter to memorize a script. Instead, the manipulations were built into the materials; we hoped this would reduce and possibly even eliminate suspiciousness by the participants about the experiment.

As in Experiment 1, participants were asked to return a verdict and to assess the likelihood that the defendant was guilty of the accused crime. In addition, they were 
asked whether any particular witness's testimony had been especially influential in their determination of guilt. We were interested in whether the objection or interruption would cause participants to say that they had relied more (or less) on the objected-to testimony and whether their designation of particular testimony as influential was related to their verdicts.

\section{Method}

\section{Participants}

A total of 326 undergraduates at the University of Virginia participated for psychology course credit. Seventeen participants responded that they had previously seen the episode of Law and Order used in the study, so their data was excluded from analysis. After this exclusion, there were 120 male and 179 female participants, as well as 10 people who did not respond to the gender question; participants ranged in age from 17 to 25 . Groups of up to12 students participated in the study at one time.

\section{Materials and Procedure}

Participants first read and listened to instructions and background information about a criminal case. Then they watched a one of three versions of videotape depicting a segment of the criminal trial. The defendant in the trial was accused of having contributed to his wife's violent outburst, which ultimately resulted in the death of their daughter. The critical (incriminating) testimony occurred when the prosecutor asked the defendant whether he provided his wife with cocaine - a substance known to have contributed to his wife's aggression. In the versions that included an objection or interruption, it occurred immediately following this question. In all instances the question was admissible, so the defendant provided an answer. The defendant's answer 
was vague - this was intentional because it was important to create enough ambiguity that jurors could be swayed by the interruption or objection.

In the No-Objection condition, the question and answer followed without any type of disruption. The Simple-Interruption condition contained a 10-second pause in the tape-filled with alternating blank screens and "snow"- between the prosecutor's question and the defendant's answer. The Objection-Admissible condition contained an objection from the defense attorney immediately following the prosecution's question. This objection was overruled and the defendant was instructed by the judge to answer the question.

Immediately after watching the trial, participants were asked to render a verdict, rate their confidence in this verdict, and provide an opinion as to how likely it was that the defendant was guilty (regardless of verdict). They were also asked which witness, or what testimony (if any) most influenced their decision. Finally, they provided demographic information.

\section{Results and Discussion}

Results were consistent with those from Experiment 1. The proportion of guilty verdicts in each condition is shown in Figure 4.

\section{Replication of Experiment 1}

First, participants in the Simple-Interruption condition returned fewer guilty verdicts than those participants in the No-Objection condition, although unlike the results in Experiment 1, the difference was not significant (49\% versus 55\%, $\mathrm{X}^{2}(1, \mathrm{~N}=200)=$ .072). One possible reason for this difference relates to the difference in the duration of the interruption in Experiments 1 and 2. By modifying the interruption to make it less 
dramatic, it appears that we diminished the distracting nature of the interruption, lessening its effect on verdicts.

Second, as in Experiment 1, objecting to critical testimony increased guilty verdicts: the proportion of guilty verdicts in the Objection-Admissible condition (63\%) was greater than that in the No-Objection condition (55\%). However, as in both measures in Experiment 1, that difference was not significant, $\mathrm{X}^{2}[1, N=209]=1.49, n s$.

Third, also as in Experiment 1, an objection led to more guilty verdicts than a simple interruption: there were significantly more guilty verdicts in the ObjectionAdmissible condition (63\%) than in the Simple-Interruption condition (49\%), $\mathrm{X}^{2}[1, N=$ $209]=4.34, p<.05$.

These results, along with the results from Experiment 1, are important for understanding the potential dual effect of an attorney's objection. As an interruption, an objection may serves as a distraction, decreasing the impact of the testimony (here the critical testimony); however, as a signal that the testimony is important, the objection appears to increase the use of that testimony.

\section{Interruption as Distraction: Most Influential Witness Results}

Support for the idea that an interruption creates a distraction comes from the data in which participants were asked to name which witness (if any) had a particular influence on their decision about the verdict. Participants in the Simple-Interruption condition appear to have been more distracted or less attentive during the defendant's testimony (when the interruption and critical testimony occurred) as compared to participants in the other two conditions. Overall, $33 \%$ of the participants named the defendant as the most influential witness, $25 \%$ named the defendant's wife, $20 \%$ named 
the patient, $4 \%$ named a combination of two witnesses, and $19 \%$ reported that no one witnesses influenced them more than the others. Participants who indicated that the defendant was the most influential witness were more likely to find him guilty $(69 \%)$ than participants who reported another witness as being most influential (50\% guilty; $\mathrm{X}^{2}$ $[1, N=309]=10.8, p=.001)$. Significantly fewer participants in the Simple-Interruption condition thought he was the most influential witness $(22 \%)$ than in either of the other two conditions $($ No-Objection $=39 \%$; Objection-Admissible $=37 \%), \mathrm{X}^{2}(2, N=309)=$ $7.8, p=.02$.

The finding that participants were less likely to be influenced by the witness who was testifying at the time of the interruption supports the theory that interruptions serve as distractions. This result contradicts some other findings that suggest that interruptions serve to draw attention to information being presented at the point of disruption, increasing people's thoughts and later use of such information

\section{General Discussion}

The results of these two studies provide a glimpse into the unique nature of the courtroom objection. An objection conveys information to jurors that causes them to pay particular attention to the information, and ultimately, to weight it more heavily. By making explicit a desire to keep jurors from using certain damaging information, the objecting side may actually be frustrating the very goal it set out to achieve. On the other hand, a non-objection interruption can distract the listener and lessen the impact of associated information.

Experiment 1 found some support for the standard failure-to-disregard finding: participants in the Testimony-Objection-Inadmissible condition who heard the critical 
testimony, the objection, and the instruction to disregard were marginally more likely to return a guilty verdict than those in the No-Testimony condition who never heard the testimony at all. By itself, this finding tells us little about the role of the objection (or precisely what forces are at work) because any effects could be attributed to whether the jurors heard the incriminating testimony, whether there was an interruption, whether that interruption was an objection, and whether there was an instruction by the judge.

In order to explore the possibility that the objection-interruption hinders compliance with judge instructions and to determine what about the objection is important, we included two interruption conditions Although both contained an interruption, the Testimony-Objection-Admissible condition and the Testimony-SimpleInterruption condition differed in whether the interruption suggested that one side wanted to prevent the testimony from being used and whether there was a ruling (in this case that the testimony was admissible) or whether the interruption contained no meaningful information whatsoever. By comparing each of these conditions with each other and with the Testimony-No-Objection condition, we were able to pinpoint the effect of the objection itself. Relative to the Testimony-No-Objection condition, the introduction of a simple interruption dramatically decreased use of the testimony and therefore guilty verdicts. However, relative to the Simple-Interruption condition, the ObjectionAdmissible condition dramatically increased guilty verdicts., What does the ObjectionAdmissible condition add? Whatever it is about the objection that causes an increase in use of the testimony must be related to its potential for conveying information to jurors. Specifically, an objection may signal jurors that the testimony has particular importance because of its potential to harm one side. 
In light of the evidence (pun intended, again) that the objection serves as this type of signal, it appears that theories of belief perseverance, correction comprehension, story coherence, hindsight bias, and justice (whichever one subscribes to), cannot be the whole story. Where there is an objection, there is a cue to jurors that the objecting attorney is worried about the objected-to testimony. It seems likely that at least part of the reason why jurors fail or are imperfect at disregarding is that they are deriving meaning from the objection in this fashion.

An astute reader will have noticed that our design confounded an attorney's objection with a judge's ruling: both conditions containing an objection also included a ruling. The judge's instruction is the basis for two theoretical explanations for jurors' failure to follow instructions to disregard. First, reactance theory posits that jurors resent the perceived threat to their freedom to use what information they see fit in rendering a decision. Second, the ironic processes theory states that when individuals are instructed not to think of something, that thing becomes more, rather than less likely to come to mind. However, neither explanation holds up well against all of the data. With respect to reactance theory, when jurors are told not to use the critical testimony they do anyway (they fail to perfectly follow instructions to disregard). However, when the judge explicitly instructs them to use the critical testimony, they also do (the TestimonyObjection-Admissible condition yielded a greater number of guilty verdicts than Testimony-No-Objection and Testimony-Simple-Interruption). Jurors would appear to be reacting against one instruction but not the other. Because this explanation does not make sense, it would seem that reactance is not the explanation for juror behavior. Ironic processes theory also succeeds at explaining the standard effect but has nothing to say 
about the conditions in which the testimony is present and participants are allowed to use it (i.e., it is not "ironic" to exhibit an increased use of information that one is told to use.) Therefore, we are left with our preferred explanation of the data: jurors want to use information that they perceive lawyers deem particularly important or potentially dangerous, in other words, information that lawyers want kept out of the decision-making process.

These results, have implications for litigators' objection strategy. We found that although jurors are imperfect at following instructions to disregard, exposure to an admonition can decrease their use of incriminating testimony. This finding suggests that a well-placed objection can achieve the desired effect - but only when the ruling favors the objecting party. An objection that is overruled can, far from succeeding in minimizing the influence of testimony, exacerbate damage caused by harmful information. An attorney who appears to fear jurors' use of incriminating evidence ignites suspicion in jurors. Unlike an objection, a simple interruption (such as a break in the courtroom action for a recess) appears to distract jurors from testimony that immediately precedes the interruption. Future research might explore the boundaries of this effect to determine whether bringing out damaging evidence immediately prior to a recess diminishes its impact on verdicts.

Finally, although more work must be done, we have gained invaluable insight into how interruptions, and specifically objection-interruptions can affect verdicts. We do not claim that a desire to use information that a lawyer wants to omit is the sole explanation for all of the failure-to-disregard findings. We have, however, added to the theoretical framework that may explain this troubling phenomenon. 


\section{References}

[This paper was submitted for publication in this form in 2005/06 before the Steblay et al. meta-analysis was published.]

Anderson, C. A., Lepper, M. R., \& Ross, L. (1980). Perseverance of social theories: The role of explanation in the persistence of discredited information. Journal of Personality and Social Psychology, 39, 1037-1049.

Baddeley, A. D., \& Hitch, G. (1993). The recency effect: Implicit learning with explicit retrieval? Memory \& Cognition, 21, 146-155.

Brehm, S. S., \& Brehm, J. W. (1981). Psychological reactance. New York: Academic Press.

Broeder, D. (1959). The University of Chicago jury project. Nebraska Law Review, 38, 744-760.

Caretta, T. R., \& Moreland, R. L. (1983). The direct and indirect effects of inadmissible evidence. Journal of Applied Social Psychology, 13, 291-309.

Clavet, G. J. (1996). Ironic effects of being told to 'disregard the evidence': Saying what's on your mind. Dissertation Abstracts International: Section B: The Sciences and Engineering, 56, 5222.

Eccleston, C., \& Crombez, G. (1999). Pain demands attention: A cognitive-affective model of the interruptive function of pain. Psychological Bulletin, 125, 356-366.

Edwards, K., \& Bryan, T. S. (1997). Judgmental biases produced by instructions to disregard: The (paradoxical) case of emotional information. Personality and Social Psychology Bulletin, 23, 849-864. 
Fein, S., McCloskey, A. L., \& Tomlinson, T. M. (1997). Can the jury disregard that information? The use of suspicion to reduce the prejudicial effects of pretrial publicity and inadmissible testimony. Personality and Social Psychology Bulletin, $23,1215-1226$.

Fischhoff, B. (1975). Hindsight $\neq$ foresight: The effect of outcome knowledge on judgment under uncertainty. Journal of Experimental Psychology: Human Perception and Performance, 1, 288-299.

Geiger, S., \& Reeves, B. (1993). We interrupt this program. . Attention for television sequences. Human Communication Research, 19, 368-387.

Geiselman, R. E. (1974). Positive forgetting of sentence material. Memory and Cognition, 2, 677-682.

Gilbert, D. T., Tafarodi, R. W., \& Malone, P. S. (1993). You can't not believe everything you read. Journal of Personality and Social Psychology, 65, 221-233.

Glanzer, M., \& Cunitz, A. R. (1966). Two storage mechanisms in free recall. Journal of Verbal Learning and Verbal Behavior, 5, 351-360.

Johnson, J. T., \& Seifert, C. M. (1994). Sources of the continued influence effect: When misinformation in memory affects later inferences. Journal of Experimental Psychology: Learning, Memory, and Cognition, 20, 1420-1436.

Kassin, S. M., \& Sommers, S. R. (1997). Inadmissible testimony, instructions to disregard, and the jury: Substantive versus procedural considerations. Personality and Social Psychology Bulletin, 23, 1046-1054.

Kassin, S. M., \& Studebaker, C. A. (1998). Instructions to disregard and the jury: Curative and paradoxical effects. In J. M. Golding \& C. M. MacLeod (Eds.), 
Intentional forgetting: Interdisciplinary approaches (pp. 413-434). Mahwah, NJ: Erlbaum.

Krugman, H. E. (1983). Television program interests and commercial interruption. Journal of Advertising Research, 23, 21-23.

Lewin, K. (1928). Untersuchungen zur Handlungs-und Affectpsychologie. VI.

Ovsiankina M. Die Wiederaufnahme unterbrochener Handlungen [Investigations on the psychology of action and affection. VI The resumption of interrupted acts]. Psychologische Forschung, 11, 302-389.

Lubet, S. (1997). Modern trial advocacy: Analysis and practice (2nd ed.). USA: National Institute for Trial Advocacy.

Maentylae, T., \& Sgaramella, T. (1997). Interrupting intentions: Zeigarnik-like effects in prospective memory. Psychological Research, 60, 192-199.

Pennington, N., \& Hastie, R. (1992). Explaining the evidence: Tests of the story model for juror decision-making. Journal of Personality and Social Psychology, 62, 189206.

Rachlinksi, J. J. (2000). A positive psychological theory of judging in hindsight. In C. R. Sunstein (Ed.), Behavioral law and economics (pp. 95-115). Cambridge: Cambridge University Press.

Reinard, J. C., \& Reynolds, R. A. (1978). The effects of inadmissible testimony objections and rulings on jury decisions. Journal of the American Forensic Association, 14, 91-109. 
Sue, S., Smith, R. E., \& Caldwell, C. (1973). Effects of inadmissible evidence on the decisions of simulated jurors: A moral dilemma. Journal of Applied Social Psychology, 3, 345-353

Tanford, J. A. (1990). The law and psychology of jury instructions. Nebraska Law Review, 69, 71-111.

Thapar, A., \& Greene, R. (1993). Evidence against a short-term store account of longterm recency effects. Memory \& Cognition, 21, 329-337.

Thompson, W. C., Fong, G. T., \& Rosenhan, D. L. (1981). Inadmissible evidence and juror verdict. Journal of Personality and Social Psychology, 40, 453-463.

Trabasso, W. C., \& van den Broek, P. W. (1985). Causal thinking and the representation of narrative events. Journal of Memory and Language, 24, 595-611.

Wegner, D. M. (1994). Ironic processes of mental control. Psychological Review, 101, 34-52.

Wegner, D. M., \& Erber, R. (1992). The hyperaccessibility of suppressed thoughts. Journal of Personality and Social Psychology, 63, 903-912.

Wegner, D. M., Schneider, D. J., Carter, S., III, \& White, T. (1987). Paradoxical effects of thought suppression. Journal of Personality and Social Psychology, 53, 5-13.

Williams, K. D., Loftus, E. F., \& Deffenbacher, K. A. (1992). Eyewitness evidence and testimony. In D. K. Kagehiro \& W. S. Laufer (Eds.), Handbook of psychology and law (pp. 141-166). New York: Springer-Verlag.

Wolf, S., \& Montgomery, D. A. (1977). Effects of inadmissible evidence and level of judicial admonishment to disregard on the judgments of mock jurors. Journal of Applied Social Psychology, 3, 205-219. 
Zeigarnik, B. (1927). Das Behalten erledigter und unerledigter Handlungen [Keeping settled and incomplete actions]. Psychologische Forschungen, 9, 1-85. 
Figure 1. Experiment 1 conditions.

\begin{tabular}{|c|c|c|c|c|c|}
\hline & Is Critical & Does & Does & Ruling & May \\
& Testimony & Interruption & Objection & & Testimony \\
Present? & Occur? & Occur? & & Be Used? \\
\hline No- & No & No & N/A & N/A & N/A \\
\hline $\begin{array}{c}\text { Testimony } \\
\text { No- }\end{array}$ & Yes & No & No & N/A & Yes \\
Objection & Yes & Yes & Yes & Sustained & No \\
\hline $\begin{array}{c}\text { Testimony- } \\
\text { Objection- } \\
\text { Inadmissible }\end{array}$ & & & & (Disregard) & \\
\hline $\begin{array}{c}\text { Testimony- } \\
\text { Objection- } \\
\text { Admissible }\end{array}$ & Yes & Yes & Yes & Overruled & Yes \\
\hline $\begin{array}{c}\text { Testimony- } \\
\text { Simple- } \\
\text { Interruption }\end{array}$ & Yes & Yes & No & N/A & Yes \\
\hline
\end{tabular}


Figure 2. Percent Guilty Verdict (Dichotomous Measure) in Experiment 1.

Figure 2. Percent guilty verdicts (dichotomous measure) in Experiment 1.

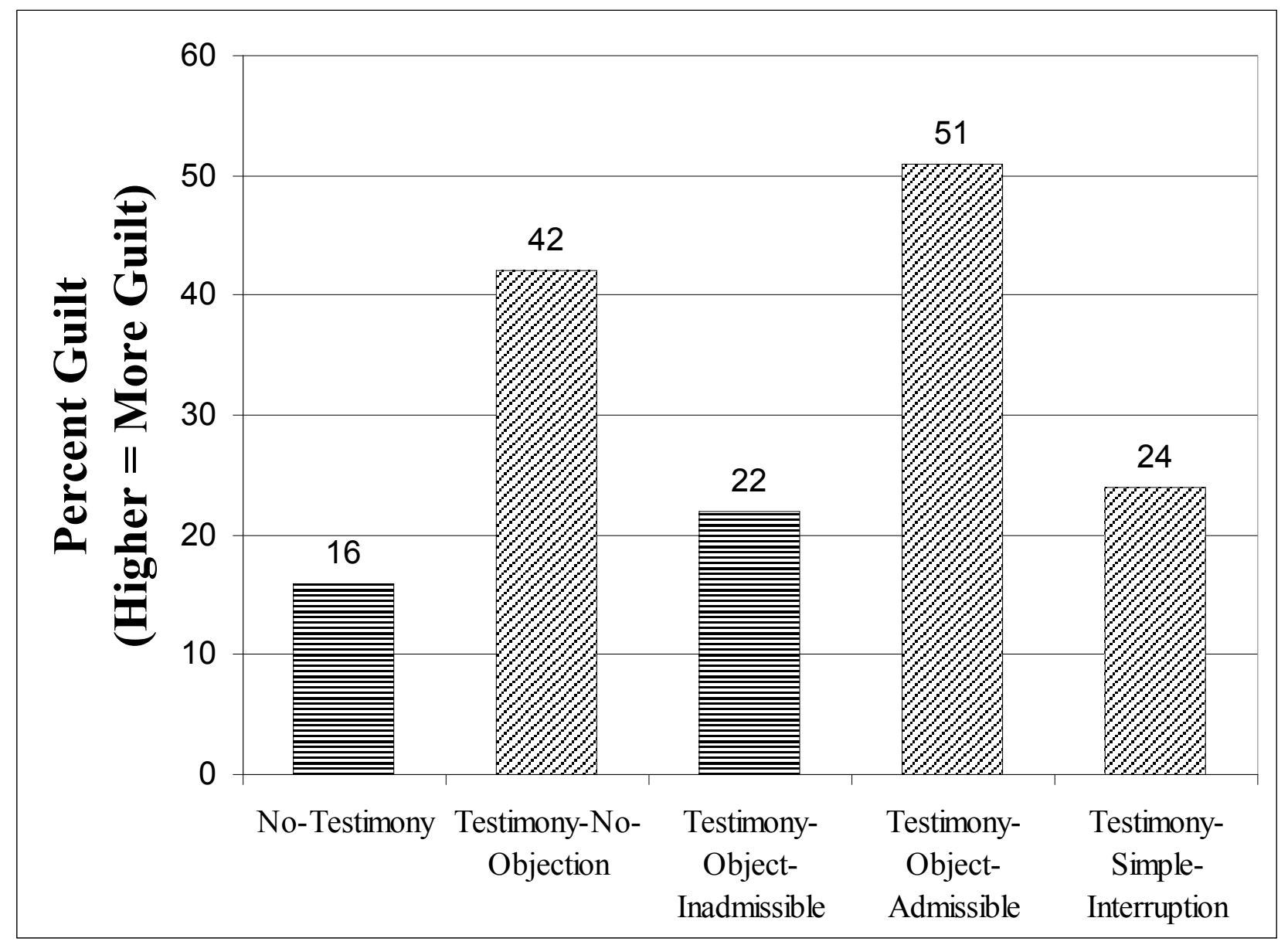

Note: Lighter bars show conditions in which critical testimony was present and allowed to be used. Failure to disregard incriminating evidence is demonstrated when participants in the Testimony-Objection-Inadmissible condition return more guilty verdicts than participations in the No-Testimony condition. Some ability to disregard incriminating evidence is demonstrated when Testimony-Objection-Inadmissible is less than Testimony-Objection-Admissible. We added the Testimony-No-Objection and Testimony-Simple-Interruption conditions to investigate the role of the objection as an interruption per se. 
Figure 3. Scaled guilt ratings (0-9) in Experiment 1. (Lighter bars show conditions in which critical testimony was present and allowed to be used.)

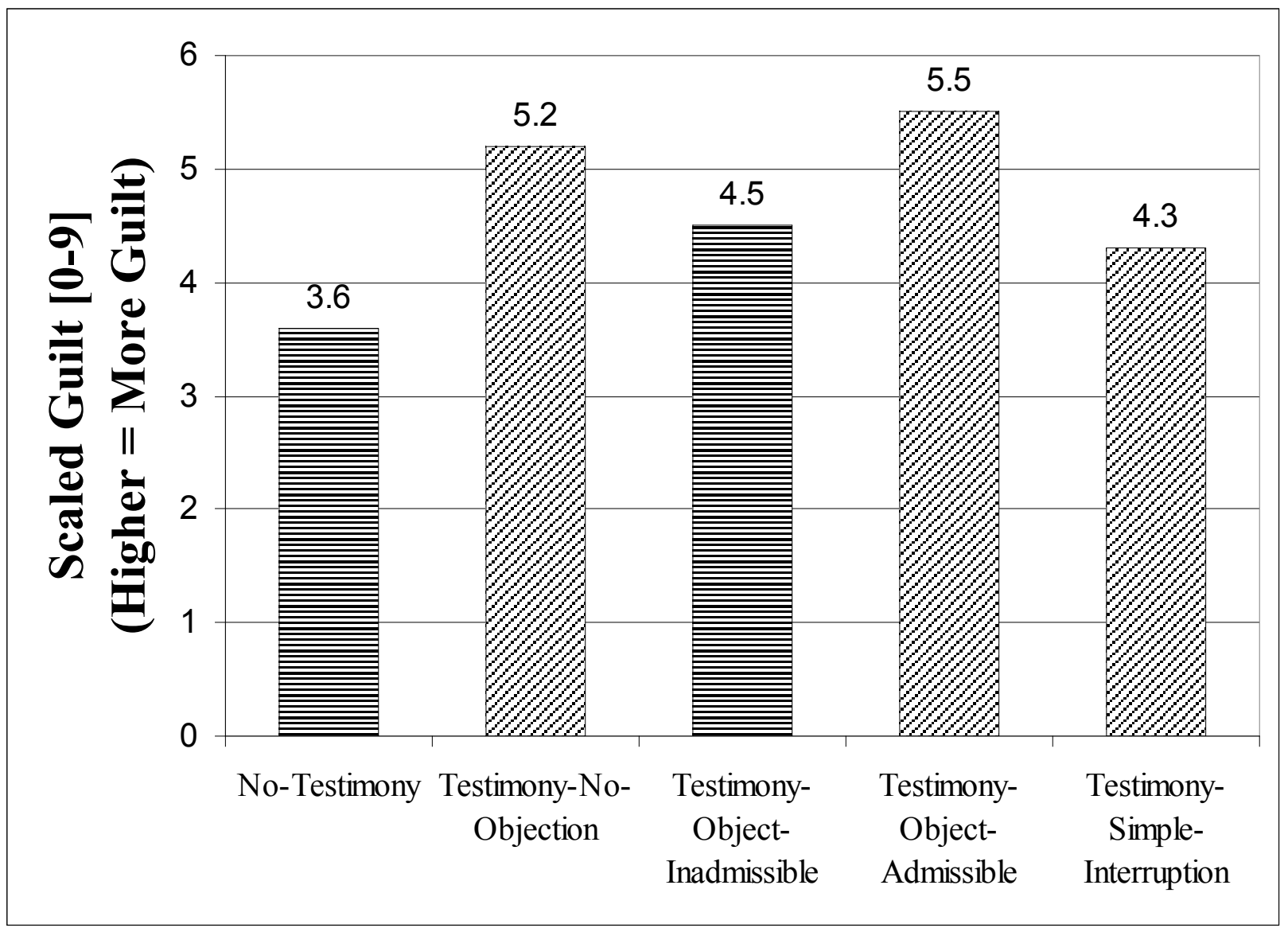


Figure 4. Percent guilty verdicts in Experiment 2. (Lighter bars show percentages from Experiment 1.)

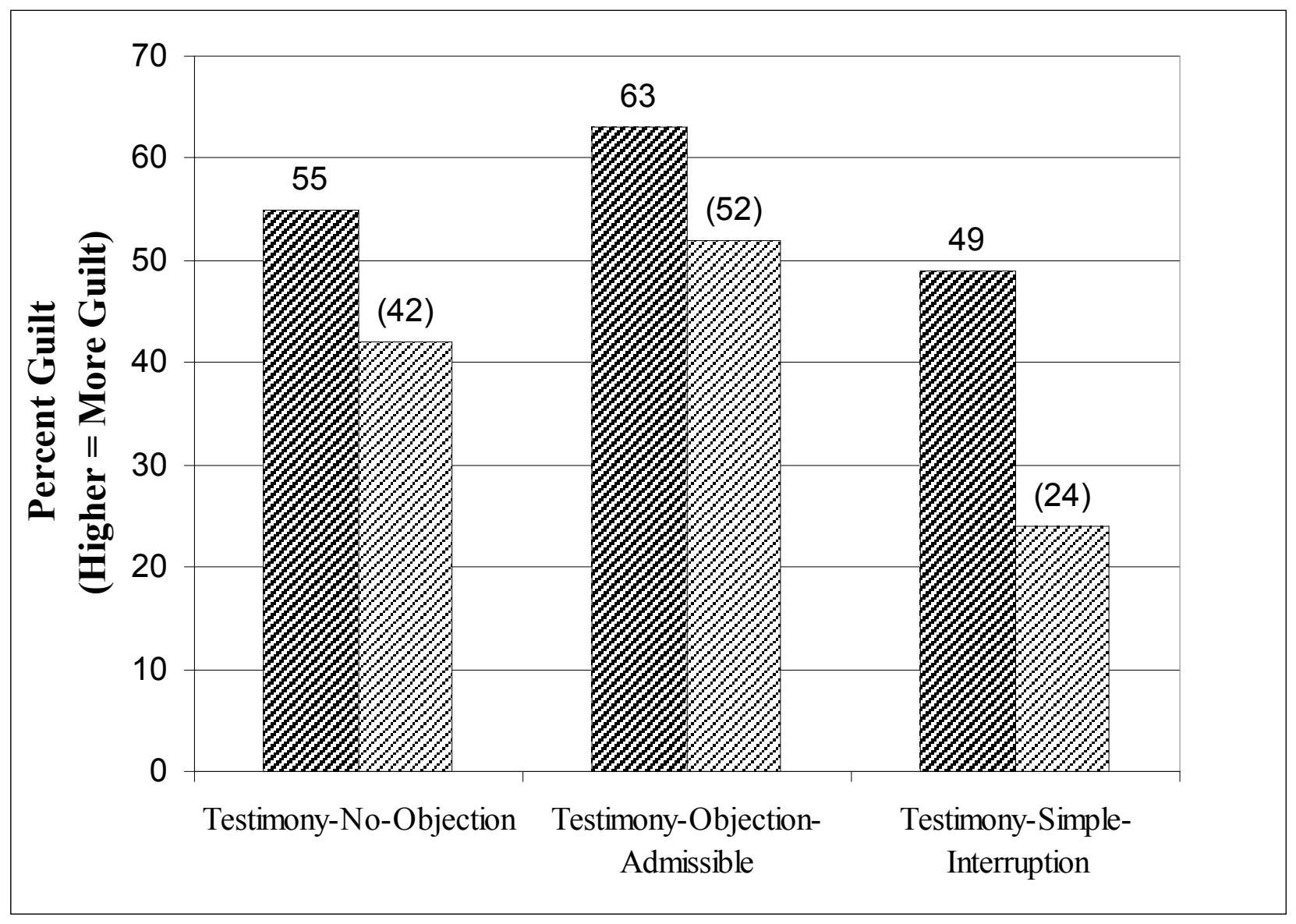

